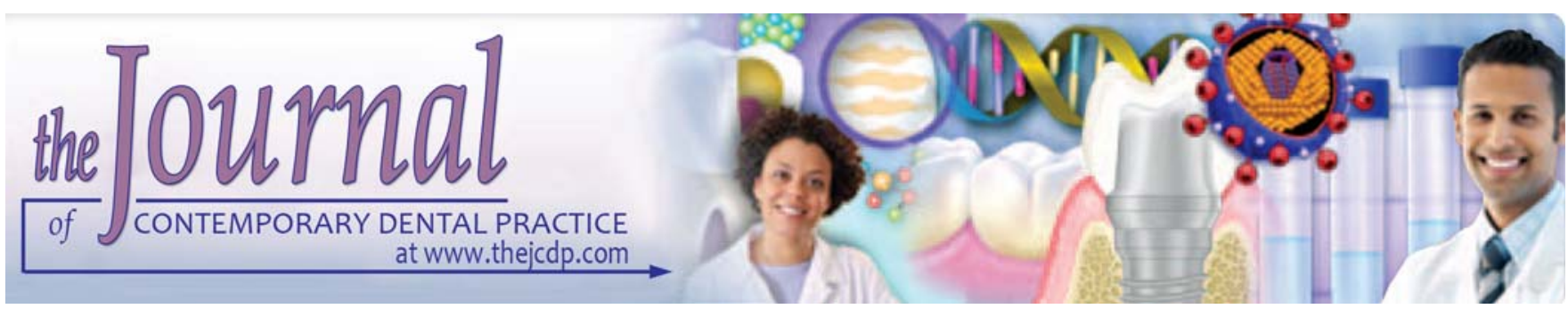

\title{
An Aggressive Lesion of Anterior Maxilla
}

\author{
Durga Rajaram Okade, Leena James, Akshay Shetty, Sudhakara Reddy
}

\section{ABSTRACT}

Aim: To understand the aggressiveness of lesions in immunocompromised patients.

Central giant cell granuloma (CGCG) is a non-neoplastic intraosseous lesion, anterior to the molars and more commonly in the mandible. It is an uncommon lesion accounting for less than $7 \%$ of all benign jaw lesions found predominantly in children and young adults with a female predilection of about 2:1 ratio.

Case description: A 22-year-old male patient came to the department with a growth in the anterior part of the maxilla with pain, rapid pace of growth and which recurred after initial excision as told to us in the case history.

Conclusion: A diagnosis of CGCG of aggressive nature should be kept in mind, in a young immunocompromised patient.

Clinical significance: A recurrent lesion, with rapid pace of growth, associated with pain, a positive immunodeficient status, lesion in the anterior maxilla in a male patient, we can think of an aggressive $C G C G$.

Keywords: Central giant cell granuloma, Aggressive, Immunocompromised, Anterior maxilla.

How to cite this article: Okade DR, J ames L, Shetty A, Reddy S. An Aggressive Lesion of Anterior Maxilla. J Contemp Dent Pract 2012;13(6):930-933.

\section{Source of support: Nil}

Conflict of interest: None declared

\section{BACKGROUND}

Central giant cell granuloma is a rare lesion, behaving in a way which is often unpredictable, varying from a slowly growing swelling to a highly aggressive, painful lesion. ${ }^{1}$ It is seen in all age groups ranging from 2 to 80 years, but more than $60 \%$ of the cases occur under the age of 30 years. ${ }^{2}$

$\mathrm{Jaffe}^{3}$ described the lesion as giant cell reparative granuloma owing to the formation of the lesion as a result of jaw trauma and intraosseous hemorrhage.

When there is a jaw trauma, there is an intramedullary hemorrhage, when the blood supply is totally cut off it leads to the formation of a traumatic bone cyst, when it is fully maintained it forms the arteriovenous malformation and when the blood supply is partially cut off it forms the central giant cell granuloma. ${ }^{4} \mathrm{~A}$ lthough the etiology is unknown, there are many proposed hypothetical pathogenesis of the lesion given by Pogrel. ${ }^{5}$

$\mathrm{Here}$, there is a case report of a rare aggressive form of central giant cell granuloma in the anterior maxilla in an immunocompromised patient.

\section{CASE REPORT}

A 22-year-old male patient reported to the Department of Oral Medicine and Radiology in SDM College of Dental Sciences and Hospital, Dharwad, K arnataka with a chief complaint of a growth in the upper right side front region of the jaw since 2 months. He also reported of a similar grow th previous to the present one 6 months back which he got removed and it recurred again. In the history of presenting illness, he recalled that the growth was the size of a peanut which rapidly increased to its present size associated with severe pain, aggravated during eating and no relieving factors. The patient was moderately built and nourished. On extraoral examination, there was a mild facial asymmetry on inspection with a diffuse swelling in the upper front region of the jaw toward the right side obliterating the nasolabial fold, oval in shape, ill-defined margins, measuring roughly $2 \mathrm{~cm}$ in size, color over the swelling was normal. On palpation, it was firm in consistency, tenderness present and no rise in temperature. On intraoral examination, in the soft tissue examination, presence of a soft tissue grow th with well-defined margins causing labial cortical plate expansion red in surface color, surface over the growth appears lobulated, extending anteriorly from the alveolar ridge between 11 and 12 causing displacement of 12, extending to the palatal aspect of 13 (Fig. 1). On palpation, it was firm in consistency, with a sessile base, did not blanch on pressure and tender on palpation.

In the hard tissue examination, presence of $11,21,22$, 23 and 24 with deep attrition, discoloration, displaced 11, 


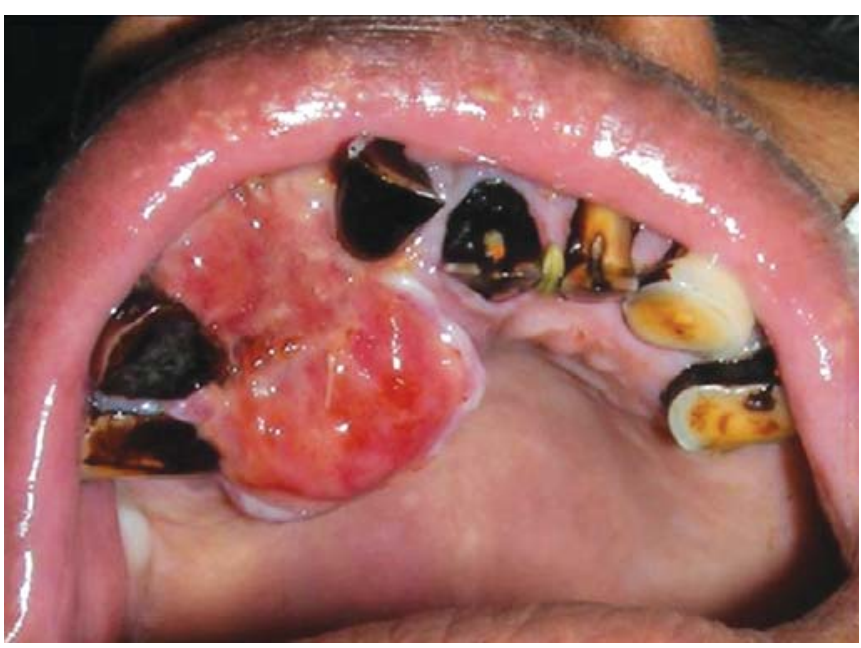

Fig. 1: Soft tissue growth posteriorly onto the palatal aspect of 13 , well-defined margins, lobulated surface and a sessile base

12 due to the presence of the growth. The lower arch teeth had periodontally compromised teeth with marked mobility with all teeth. A $n$ incisional biopsy was performed and sent for histopathological examination. We also asked for his immune status to be assessed owing to the presence of this aggressive lesion and his periodontal status at a young age.

An orthopantomogram (OPG), intraoral periapical (IOPA) and occlusal radiographs were advised for the patient. Orthopantomogram (Fig. 2) revealed a diffuse solitary unilocular radiolucency with no sclerotic margins causing osteolysis of the alveolar ridge region between 11 and 12 causing displacement of 12 and root resorption of 11. In the lower arch, vertical and horizontal bone loss almost to the apical 3rd of all the posterior teeth and missing upper premolars and molars.

The intraoral periapical radiograph revealed an osteolytic lesion in the region of 11 causing its root resorption and displacing 12 (Fig. $3 \mathrm{~A}$ ) and same was seen in the occlusal radiograph (Fig. 3B).

Histopathological findings revealed intraosseous lesions with cellular fibrous tissue, multiple foci of hemorrhage,

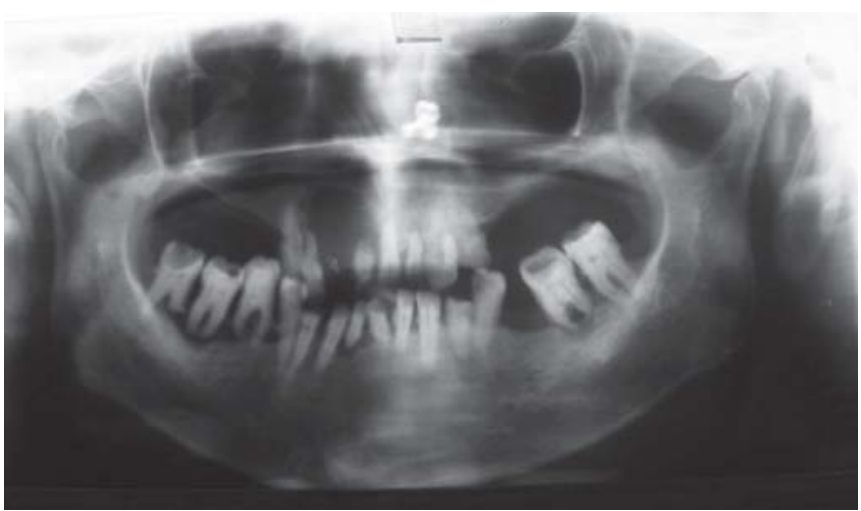

Fig. 2: Orthopantomogram reveals a well-defined unilocular osteolytic lesion in the right anterior maxilla displacing 11 and 12 , causing root resorption of 11 and 12 and other periodontally compromised teeth
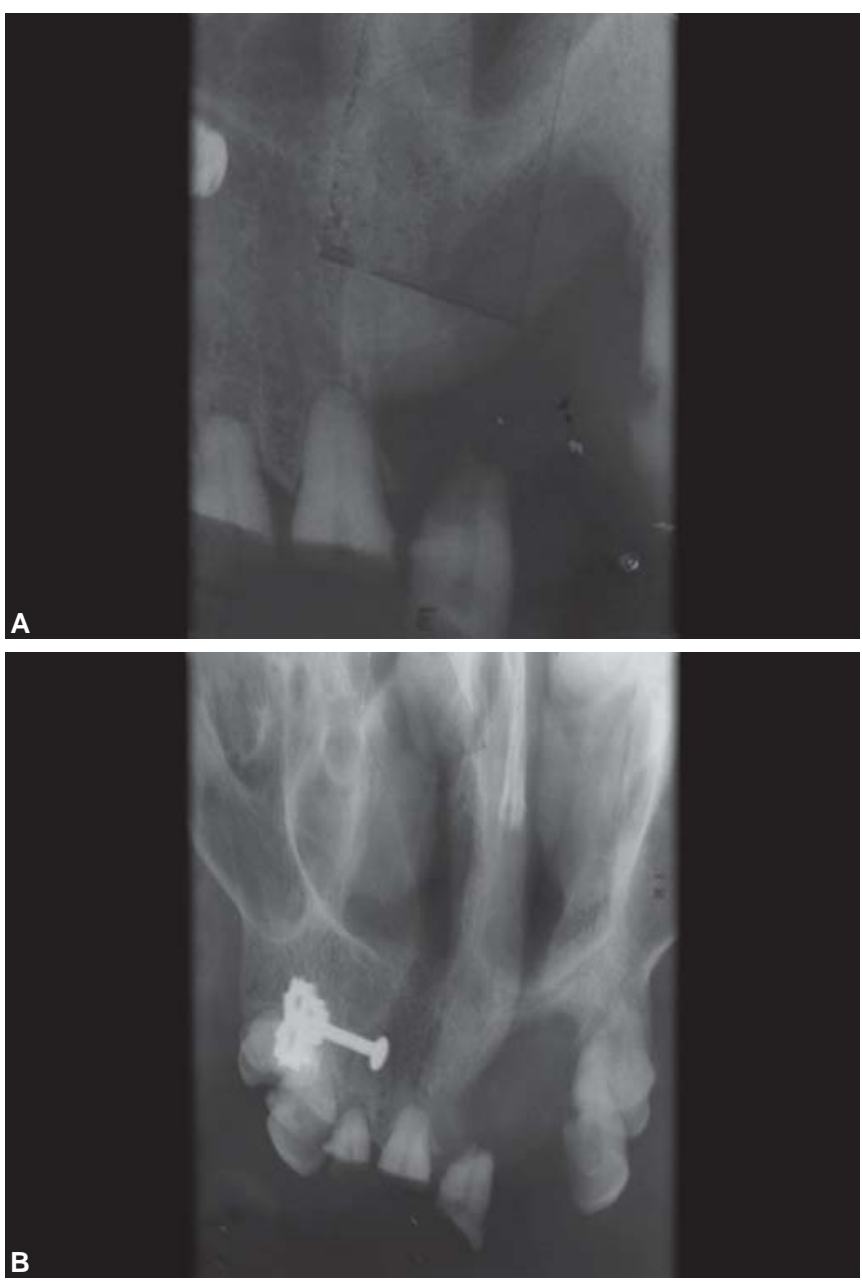

Figs $3 A$ and B: Intraoral periapical and maxillary occlusal radiographs respectively reveal an osteolytic lesion in the region of 11 causing its root resorption and displacing 12

aggregation of multinucleated giant cells (Fig. 4). This histopathological report gave us the confirmation of central giant cell granuloma. The patient underwent excision of the growth, also returned to us with a positive HIV status report for which the patient is taking antiretroviral therapy for the same.

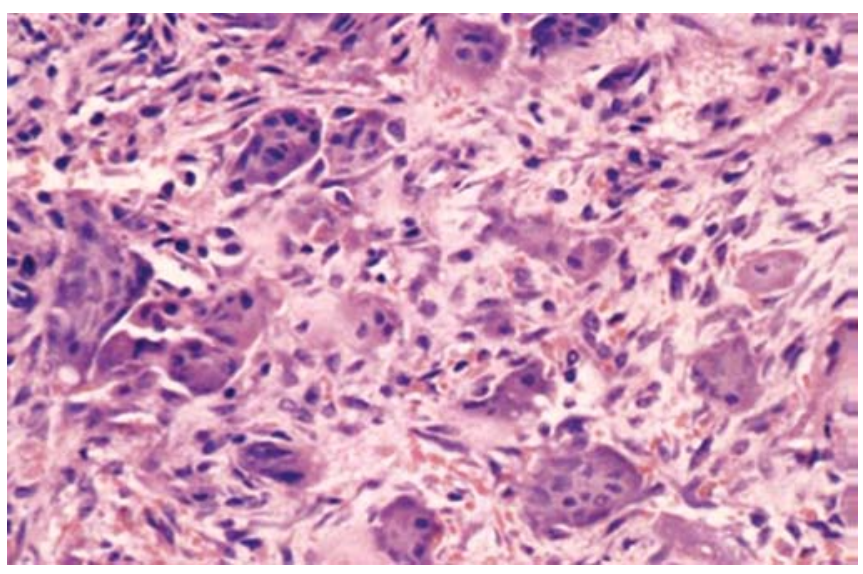

Fig. 4: Intraosseous lesions with cellular fibrous tissue, multiple foci of hemorrhage, aggregation of multinucleated giant cells 


\section{DISCUSSION}

Pogrel ${ }^{5}$ has given the hypothetical pathogenesis of central giant cell granuloma as it could be arising out of an epigenetic event which causes the tumor spindle cells within the mesenchyme of the bone marrow to proliferate and produce the central giant cell granuloma. These tumor spindle cells could al so produce cytokines which bring about the recruitment of tumor spindle cells to the capillaries which release monocytes and these differentiate to osteoclastic tumor giant cells which bring about resorption and then formation of the central giant cell granuloma.

Central giant cell granuloma was classified by the W orld Health Organization in $2005^{6}$ as a rarely aggressive idiopathic benign intraosseous lesion that occurs almost exclusively in the jaws.

In our case the lesion recurred in the same region after excision and had grown to a large size within a short span of time, which emphasizes that the lesion was of aggressive nature, which is a rare occurrence. These lesions are commonly found in the mandible anterior to the molars, in femal e patients, whereas in our case the patient was a young male patient with the lesion in the anterior maxilla. Considering that the lesion was of recurrent and aggressive nature and his poor periodontal condition at a young age, we asked for his HIV status to be assessed, which turned out to be positive.

For many years, this lesion has been discussed with giant cell tumor of bone and other related lesions such as hyperparathyroidism, reparative response to injury, aneurysmal bone cyst, fibrous dysplasia, nonossifying fibroma and cherubism. All these manifest as intrabony lesion, showing giant cells microscopically. ${ }^{7}$

The abnormality may be disclosed as a purely incidental finding during radiographic examination of the jaws made for an unrelated purpose. In only about $25 \%$ of the cases, the lesion is accompanied by pain. The lesions develop without paresthesia. Teeth in association with the lesion may become mobile but maintain their vitality. ${ }^{8}$

O ur case was associated with pain, swelling, displacement of teeth, recurrence of the lesion after it was excised 6 months back. Recurrence, rapid growth of the lesion and associated with pain substantiates its aggressiveness.

$M$ any studies ${ }^{6}$ have showed that the lesions are more common in the anterior segments of the jaws and can even cross the midline. Most of the cases of central giant cell granuloma occur on the right side of the jaw as compared with the left side. ${ }^{7}$ The radiological features vary from illdefined destructive lesions to multilocular radiolucency in the mandible, splaying of the roots are seen in the region adjacent to the lesion. ${ }^{9}$ Some authors have seen the trend that larger lesions have a multilocular appearance, ${ }^{10}$ w hereas in our case, an ill-defined unilocular radiolucency was seen causing displacement of central and lateral incisors of the maxilla on the right side.

The World Health Organization ${ }^{11}$ has defined it as an intraosseous lesion consisting of cellular fibrous tissue that contains multiple foci of hemorrhage, aggregations of multinucleated giant cells and occasionally trabeculae of woven bone.

In our case with the clinical findings, history, radiographic features and presence of giant cells and hemorrhage in the histopathology report which is pathognomonic, we came to the final diagnosis of central giant cell granuloma.

\section{CONCLUSION}

Central giant cell granuloma is rare in the maxillary anterior region and in males. It should be included as one of the differential diagnosis for the growth in the maxillary anterior region although it is more common in the mandible anterior to the molars and in females.

\section{ACKNOWLEDGMENT}

The author would like to thank his Postgraduate Head of Department and guide Dr V enkatesh Naikmasur and Dr A tul $P$ Sattur for helping him with this case.

\section{REFERENCES}

1. Kruse-Lösler B, Diallo R. Central giant cell granuloma: A clinical, radiologic and histologic study in 26 cases. Oral Surg Oral M ed Oral Pathol Oral Radiol Endod 2006 M ar;101(3):34654.

2. E isenbud L, Stern M, R othberg M , Sachs SA. Central giant cell granuloma of the jaws: Experiences in the management of thirtyseven cases. J Oral M axillofac Surg 1988 M ay;46(5):376-84.

3. M urphy MD, Nomikos GC. Radiographic features of central giant cell granuloma of the jaw. Radiographics 2001;21:12831309.

4. Langlais RP, Langland OE, Nortje CJ. Multilocular radiolucencies (Ch 13). Diagnostic I maging of the Jaws (1st ed). p. 351.

5. Pogrel MA. Calcitonin therapy for central giant cell granuloma. J Oral M axillofac Surg 2003; (61):649-53.

6. Nicolai G, Lore B, M ariani G, Bollero P, De M arinis L, Calabrese L. Central giant cell granuloma of jaws. J Craniofac Surg $2010 \mathrm{M}$ ar;21(2):383-86.

7. Sidhu NS, Prakash H, Sidhu SS. Central giant cell granuloma of the jaws: Review of 19 cases. B J O Oral M axillofac Surg1995 Feb; 33(1): 43-46.

8. Sholapurkar A A, Pai K M , A hsan A. Central giant cell granuloma in the anterior maxilla. Indian J Dent Res 2008 JanMar;19(1):78-82.

9. Cohen M A, H ertzanu Y . Radiographic features, including those of computed tomography, of central giant cell granuloma of the 
jaws. Oral Surg Oral Med Oral Pathol 1988 Feb;65(2): 255-61.

10. Kaffe I, Ardekian L, Taicher S, Littner M M, Buchner A. Radiological features of central giant cell granuloma of jaws. Oral Surg Oral M ed Oral Pathol Oral Radiol Endod 1996 J un;81 (6):720-26.

11. A hmed S, Babu I, Priya SP. Central giant cell granulomaa case report. J Oral Maxillofac Pathol 2003;7(1):11-14.

\section{ABOUT THE AUTHORS}

\section{Durga Rajaram Okade (Corresponding Author)}

Senior Lecturer, Department of Oral M edicine and Radiology, Sri Rajiv Gandhi College of Dental Sciences and Hospital, Bengaluru Karnataka, India, e-mail: dr_durga@ hotmail.com

\section{Leena James}

Reader, Department of Oral M edicine and R adiology, Sri Rajiv G andhi College of Dental Sciences and H ospital, B engal uru, K arnataka, India

\section{Akshay Shetty}

Reader, Department of Oral and Maxillofacial Surgery, Sri Rajiv Gandhi College of Dental Sciences and Hospital, Bengaluru Karnataka, India

\section{Sudhakara Reddy}

Senior Lecturer, Department of O ral and M axillofacial Surgery, Sri Rajiv Gandhi College of Dental Sciences and Hospital, Bengaluru Karnataka, India 